\title{
In Search of Sustainable Social Impact: A System Dynamics Approach to Managing Nonprofit Organizations Operating in Multi- Project Contexts
}

\author{
Ibrian Caramidaru $^{1 *}$, and Andreea Ionica $^{1}$ \\ ${ }^{1}$ University of Petrosani, Str. Universitatii nr.20, Petrosani, Romania
}

\begin{abstract}
Nonprofit organizations are typically seen as institutional settings that contribute to finding grassroots solutions to various social problems. But in their own turn, these entities exhibit by design manyfold frailties given by factors such as - precarious funding sustainability, balancing the multiple and, at times, divergent interests of stakeholders, finding a suitable manner to assess managerial performance. The aim of this paper consist in employing a system dynamics approach to modelling the managerial behaviour of nonprofit entities delivering their output through project networks. The system dynamics concepts of causal loops, stocks and flows dependencies are used to depict the complex relationships between projects, funding sources and social outcomes. This approach leads to identifying the systemic threatening to nonprofit sustainability and the dynamic nature of managerial decisions in the context of the interactions between nonprofit organizations, their beneficiaries and funding agencies.
\end{abstract}

\section{Introduction}

The system dynamics approach has been proven fruitful in getting a better descriptive venue towards the intricacies of complex systems. This approach is shown to be successful when mental models are built up using the knowledge of multiple parties, affected and affecting the system, who are engaged and empowered to find and weight alternative solutions to problems arising from a lack of understanding of system complexity and dynamic dependencies. Dynamic complex systems are generally exhibiting the following proprieties: time delays, nonlinear adaptive behaviours and policy resistance [1].

Would a system dynamics approach be a suitable perspective to enhance the sustainability of the nonprofit organizations? The paper aims at presenting, through employing a systems dynamics perspective, the feed-back loops intrinsic to the process of satisfying social needs through nonprofit multi-project delivery and the relations between the institutional stakeholders, as given by the resource flows and information transfers.

\footnotetext{
* Corresponding author: ibrian.caramidaru@gmail.com
} 
In the context of this paper, a nonprofit is defined as being an organization characterized by a restriction of non-distribution when it comes to profits (through dividends or managerial wages) [2]. This definition covers different organizational settings under the same concept, encompassing the charitable/voluntary sector, non-governmental organizations, social businesses and civil society organisms. By the multi-project characteristic, we mean organizations that supply all their outputs through a network of inter-related projects. A multi-project context refers thus to project based-organizations, portfolios or programs, which cannot be analysed and explained in terms of merely an aggregation of disparate, independent, projects.

For nonprofits achieving their missions through arrays of projects, the complexity factor is given by the multiple feed-back loops between the actors of social change and the resourcing needs for project implementation. Construing mental models, depicting causal loops and simulating stocks and flows are powerful tools for analysing various scenarios under different policies proposed for structuring and influencing the system, hence enabling strategic decision making processes to avoid, otherwise unforeseeable, pitfalls. While system dynamics simulation is more cost efficient than testing different policies in the real world, there is also the case that performing a system dynamics analysis would require additional managerial costs and, hence, identifying the adequate funding sources for such expenses. A system dynamics analysis could be marketed while pointing to the long term results of organizational learning though enhanced system thinking.

Many models of the microeconomic behaviour of nonprofits portray their social role as emerging out of contexts where markets fail and governments cannot contract to meet the needs of some social groups. The fact that nonprofits are looking for adequate funding from both the private and the public sectors is indicating that, at least to a certain degree, theories portraying the nonprofit sector as a reaction against markets and governments is ignorant of the power influences of the actual resource dependencies between the aforementioned sectors.

While there is some value in the usual model of nonprofit behaviour as palliative to market and government failures, as it happens with most microeconomic modelling, it neglects the dynamic nature of the interplay between the social actors and their mutual exchange of resources. Now then, if nonprofits are seen as institutions designed to alleviate social needs, a careful identification and exposition shall be required when it comes to the factors determining their sustainability, otherwise one would witness the dismal situation where the cure of social imbalances is itself structurally destined to failure.

The contents of this paper will deal in the next three sections with: providing a theoretical background and the method used herein, determining the meaning of nonprofit sustainability, exposing the relation between the stakeholder influence on modelling, the decision making processes and measuring social impact. The last three sections present a stock and flow model of nonprofit dynamic action, the strategic domain and options obtained in various situations of the main stocks of the system and, eventually, some concluding remarks.

\section{The system dynamics perspective - literature review and method}

Systems thinking presents many variations, some authors stress the originality of the system dynamics perspective through its roots in servomechanism engineering [3], while others point 3 to the convergences of different system theory approaches (cybernetics, general systems theory, system dynamics etc.) $[4,5]$. This paper shall mainly make use of the insights of the system dynamics approach - using causal loops and stock and flow 
diagrams, but the relevant applications of general systems theory and idealized design for multi-project nonprofit organizations shall also be employed when the context allows.

The standard system dynamics perspective aims at considering the endogenous nature of the structural causes affecting the success or the failure of goal oriented systems, but delineating the boarders of a system is a rather difficult task, since there is always the risk of being myopic towards element that are actually relevant to the outworking of the system, but which at first glance seem to be exogenous. Using the insights of Luhman's view of social systems, Valentiov observes that "it therefore seems plausible to assume that living organisms combine, as it where, the identities of open systems and operationally closed systems" [6]. In order to show the resource openness of the systems dynamics perspective, while stressing the endogenous nature of system dynamics structures, Richardson notes that in these models, "variables are materially open systems, but the loops they exhibit are causally closed" [7].

One of the weaknesses of stock and flow diagrams is that they seem to portray individuals in terms of stocks of population and not to allow for individual agency, which is described in terms of manipulating rate equations. Some authors notice that system dynamics modelling seems to work only if human behaviour could be wholly described by a set of equations [8]. This lacking is to be partially covered by coupling the system dynamics perspective with a resource dependence theory portraying the power relationships as determined by the resource flows and endowments of the agents manipulating the rates of the dynamic system [9].

Most of the relevant literature employing the system dynamics approach to nonprofit activity is focused on analysing nonprofits which have a commercial activity or fit into the category of social enterprises, these studies are done through the lenses of the tension arising between the social and the business missions of these entities $[9,10,11]$. As it is unpacked onwards, the current paper treats the business type activities of nonprofits as a special domain, to which our proposed model is more generic.

The field of project dynamics, relevant at some junctures of this study, is dealing with project specific issues such as: project control cycles, human resources management cycles and the rework cycle [12]. Considering the network of projects, applying a system dynamics approach to each project can be done in a manner, mutatis mutandis, similar to the modelling of project dynamics in the business context [13]. At the project network level, we encounter all the operational difficulties entailed by managing multiple projects with different constraints, but with shared resources, and exhibiting delays in delivery and informational flows. Project multiplicity is expressed, from a system dynamics perspective, as a problem of project human resources coupling [14]. We encounter two basic scenarios of project team constituency: one where teams are autonomous and assigned successive independent projects, another - where teams are distributed, through a project scattering rate across multiple simultaneous projects [15]. The latter scenario presents both allocative decisions, but also many difficulties on partitioning tasks, especially in complex systems where the man-month project distribution contributes more to hiding the project difficulties, than to stating them in a realistic solvable manner [16].

The method of this study consists in: presenting, based on the relevant literature, the connections between defining nonprofit sustainability, the primacy of stakeholders in decision making processes and the intricacies of measuring social impact; construing a system dynamics model of the strategic dynamic relationships for nonprofit sustainability (the causal loops and the stocks and flows diagram are built using Vensim PLE [17]), followed by a description of the strategic landscape, as it is unfolded by the spread of values for the main stocks in the model. 


\section{Multi-project nonprofit sustainability - framed by stakeholder primacy and measuring the social impact of projects}

When it comes to defining nonprofit sustainability, the notion refers, on a first approximation, to the organizational ongoing functionality, being determined, on one side, by the ability to maintain social legitimacy and credibility, and, on the other side, by the capacity to generate income flows that would allow for predictive service delivery [11]. Nonprofits depend on the funds raised for their inputs (ensuring resource sustainability) and on the acceptance of their outputs by their beneficiaries (ensuring legitimacy - social sustainability). Linked to the latter aspect, in a stock and flow model of the capacity for perpetuating organizational activity, nonprofit sustainability involves the organization being framed in this pursuit by the incoming flows of financing resources for projects and by the level of social needs, whose depletion serves as a goal of the dynamic system in which the nonprofit organization operates

Nonprofit sustainability aims, however, at something more than survival [18] - at an ability to understand, if not fully predict, the future in terms of the impact of their present decisions. There are limiting factors preventing growth or threatening the systemic stability of nonprofits. The causes of nonprofit failures (as identified in [2]) - i.e. philanthropic insufficiency, philanthropic particularism, philanthropic paternalism, and philanthropic amateurism - are rather static. Getting the bigger dynamic picture of the resourcing relations and the institutional behaviour of the parties impacting multi-project nonprofit behavior allows nonprofit management to become aware of the (at times unintentional) consequences of their actions and decision and to assess the influence of time delays bearing on informational flows.

There is nothing intrinsically valuable about the perennial character of a nonprofit endeavour, if its ongoing existence is not due to a real need it aims to address. When some social needs are covered and the contingencies that lead to their occurrence have been removed, the nonprofit might dissolve, or have to choose between modifying their beneficiaries, their location or even their mission and values. In the long run, even when ongoing structural needs are rising, if the mission statement pushes for an array of values to be promoted, there is always, in practice, a bargain prioritizing some values over others [6]. This behaviour might be regarded as opportunistic, but form a different venue - if a nonprofit project team has shown its efficiency in solving social problems, dissolving it, for the sake of abstract missional consistency, will actually lead to postponing, or missing, the chance for other similar problems to be solved.

In nonprofit contexts, identifying the stakeholders, their influence and importance, is key for mapping organizational constituency and environment. Whereas, in a market context, there is an ongoing information flow between producers and customers that is mediated by prices, the nonprofit entities have to create settings where an ongoing contact with their beneficiaries is facilitated. A distinction between measuring social outcome and impact and the return on investment for economic projects consists in that the latter can be sold as investment opportunities [19]. From another point of view, still there is a funding competition and market for nonprofit projects, even if the criteria used by donors for the selection of project financing decisions might not require the estimated values of forecasted outcomes. In this perspective, the value of financing represents the price of the project as a process, the project representing a mean to obtain the deliverables, which are aimed at through the financing decision.

Since nonprofits are institutions endowed by their founding members to serve a certain category of the public, taking into account multiple stakeholders - among others, board members, donors, beneficiaries - is a legal prerequisite and a moral ground for organizational legitimacy. Participative decision making is shown to be effective especially 
in case requiring innovative social solutions to public difficulties [20]. Not only is stakeholder consultation legally required and morally binding, but it is also epistemologically adequate. Enabling a quasi-democratic stakeholder consultation process for developing a system dynamics model is in tune with Forrester's suggestion to use people's "mental database" [21] which represents a repository of descriptions for the elements of the system, helping one to better capture the nature of a system as a whole. Ackoff [20] points to the social coagulation and impetus given by collective decisions making involving all the stakeholders in idealized design of systems, a process where the stakeholders witness a collectively reached and agreed upon solution to the current organizational mess.

The nonprofit boards and the long term employees represent a certain category of nonprofit stakeholders which might at times artificially depict social needs in a misleading fashion, taking advantage of the intricacies of information flow delays and the attenuation of property rights in nonprofit endowment [22]. The fact that board members and paid staff are co-interested in the perpetuity of some social status quo might be regulated by noncompensation restrictions that, akin to the non-distribution constraint, would not link managerial wages to project objectives, about which information that could be easily manipulated.

The easiest way to model nonprofit economic behavior is to see them as agents maximizing their element of output, or aiming at an optimal mix between income generating activities and nonprofit results [23]. There is true wisdom in saying that what gets measured is ultimately determining what is achieved, and choosing the appropriate metrics for social outcomes configures the multi-project activity from operational decisions in project management to strategic project intake decisions. Using logic models of project assessment [24] allows for distinguishing between project inputs, activities, outputs, outcomes and impact, where the first three serve as means for reaching the goal of supplying the last ones to society.

During the past decades, a number of methodologies have been proposed in order to fill the informational need for measuring social impact $[25,26]$. These methodologies are undergirded by a social theory of change - linking project activities to social outcomes, the latter being measured using financial proxies or shadow prices for saved social expenses or similar marketable products. The search for adequate metrics that would allow project and nonprofit activity benchmarking is itself seen at times as an unfortunate influence of a business worldview upon the nonprofit ethos. As we have noticed, the fact that nonprofits lack a system of prices for their project outputs is asking for ongoing beneficiary consultation to aim at a more objective assessment of their social outcomes. While choosing a certain instrument for assessing social impact is a vital strategic requirement, the social impact dimension should be paired with other indicators of organizational health (such as a proper transparent relation with key donors), resulting in dashboard or balanced scorecards adapted to the managerial needs of nonprofits.

\section{A stock and flow model of multi-project nonprofits}

Construing a stock and flow model begins with defining the goal of the analysed system, the goal of the real world system, of which nonprofits are an element, consists in diminishing or nullifying the identified social needs of the beneficiaries, this goal is aimed at trough supplying an array of outcomes mediated by project deliverables and resourced through contracting various financers. In terms of the prospects for an idealized design [21] of this system, the funding, the projects and the outcomes, represent the resources, the means and the goals, respectively. 
A first approximation of the feed-back loops involved in the relationships between the three main stocks and the actors providing them is portrayed in Figure. 1 below. The causal relations present a reinforcing loop between funds and project - more funding leads to more projects being developed, more effective projects legitimize an increased allocation to future projects - and a balancing loop between projects and social needs - more successful projects diminish social needs, while in increase in social needs requires more projects. If the social needs are not renewed through some social mechanism, then, after covering the need the tripartite relation will cease.

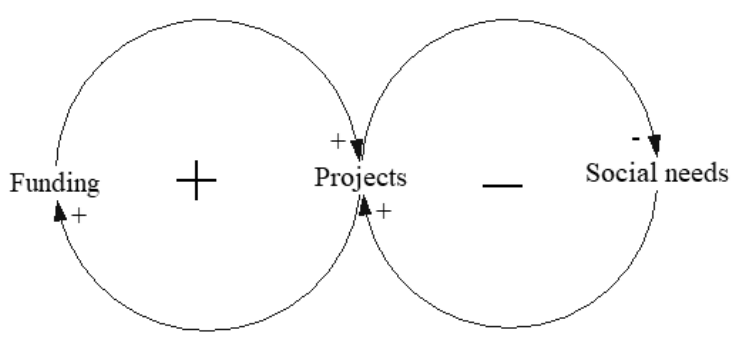

Fig. 1. The causal loop diagram of the multi-project nonprofit system

While this causal loop diagram intuitively captures the main trait of the system, it does not do justice to the intermediate processes involved in project financing and social outcomes delivery, along with the influence of delays and informational flows on the stability of the system. This modelling demand is supplied by a stock and flow diagram.

The stock and flow diagram requires specifying the limits/boundaries of the system under review, the main stocks and flow rates relevant to the system functioning and the influence of time delays and informational traffic.

If nonprofits as institutions are meant to solve the difficulties inherent in the economic system, their sustainability is key to the sustainability of a given social structure as a whole. We established the boundaries of our systemic analysis to the sources of market revenues and distributions, on one end, and to the funding and social needs sources, on the other. But this boundary setting should not deprive one from seeing the coordinating mechanisms occurring between the nonprofit sector and the other systems comprising a society.

The stock and flow model is presented in Figure 2. The drawing conventions are typical for system dynamics stock and flow diagrams: the clouds represent external sources, stocks are represented by square blocks, flows are depicted by double arrows, rates/rhythms are the taps on the flows, single line arrows represent informational flows, a double crossed single line arrow represents a delayed informational flow.

We describe four main types of stocks or levels: funds, projects, outcomes and social needs. There are also three secondary stocks: organizational balance, employees and materials. These would suffice to portray the resource and information flows in multiproject contexts, but they would have to be analyzed along with the institutional traits of the actors manipulating the flows: public or private financers, nonprofits and beneficiaries, respectively.

The stock levels offer a complete static image of the system at some point in time, for managerial purposes the rate equations and the variables affecting them are destined to account for the dynamic relationships between the stocks and the decisions reflected by the rates. While analyzing stocks and flows gives suggestions related to resource allocation problems and the effects of time delays in goal oriented settings, the institutional analysis would point to issues of power structure, informational asymmetries and reporting demands and needs. 


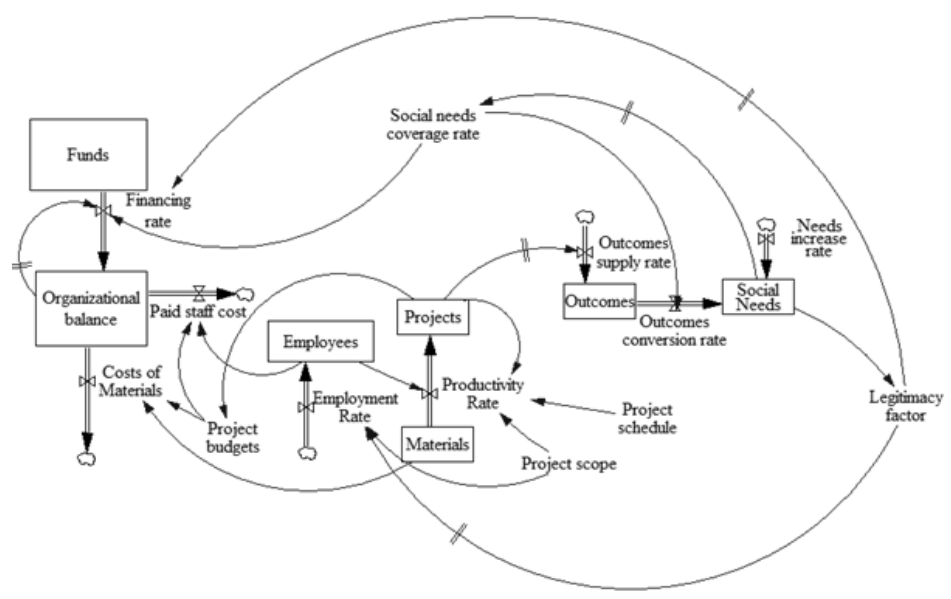

Fig. 2. The stock and flow diagram of the multi-project nonprofit system

Portraying funds as stocks might play a similar theoretical role to resource dependence theories analysing the institutional relationships through the lenses of the power distribution among the suppliers and the beneficiaries of resource traffic [9]. The funds are cash resources flowing into the organizational balance and the rhythm of the flow is determined by a financing rate. The financing rate is in its own turn determined by two auxiliary variables: the legitimacy factor and the social needs coverage rate. The latter is a constant ratio of the needs which the funders aim at covering.

Projects are defined as stocks, or inventories, of deliverables (services or products). The quantity of such a stock could be expressed in physical units or in monetary units. If the unit chosen for expressing the projects level is monetary units, then at the completion of the project life cycle the total value of the project stock has to be equal with the budget provided and consumed for that peculiar fraction of the project stock. The projects are integrations of materials transformed through a productivity rate, the productivity rate is influenced by: the level of projects, the employees stock, and two project constraints - the project scope and the project schedule. The project levels also inform the project budget, which informs the paid staff cost and the costs of materials. If projects are accumulations of deliverables a time delay occurs between the flow of funds and the social outcome supply, consisting in the project duration adjusted with the time period needed for the social outcomes to affect the beneficiaries.

Social needs are stocks of demand for social services and products, these needs are increased by social factors outside the scope of the system. Social needs are accumulations of services and products satisfying the needs of beneficiaries. The predictable character of social needs coverage might be reflected through the concept of service reliability indicating the consistent delivery, with minimum variation, of social services [9]. In order that the flow of outcomes would nullify social needs, as a matter of convention the needs could be considered in negative values. The flow between the outcomes and the needs is determined by an outcome conversion rate, informed by the goal ratio of social needs coverage rate. The level of needs also informs the social needs coverage rate leading to a balancing loop between the needs and the outcomes conversion rate. Project delivery delays, desynchronizations of the outcome conversion rate, and the delayed influence of the legitimacy factor on the financing rate, all these factors are prone to lead to heavily oscillatory behaviour of the system.

Establishing when a social need is met, or when a social problem dissolves, requires adequate metrics and verifiable criteria. The difficulty to measure the outcomes of nonprofit 
activities is in this respect enhanced by the, at times, subjective character of establishing the degree of satisfaction for various needs. This has a great deal of significance for nonprofit sustainability and mission alignment, if you do not know if (and when) you reached a certain need how do assess progress? In some cases, the project deliverables would meet one-on-one certain material lacking of the beneficiaries, but in other the scope of the project is not as easy to determine from the outset. In such a scenario, nonprofits could use means which are specific to iterative project methodologies - such as user stories for identifying needs, and "done-done" definitions for output acceptance criteria. Solutions as such have been also proposed for municipalities in search for incremental delivery and constant stakeholder approval [27]. Keeping in mind the relationship between projects and outcomes - as described in section 4 - above - and this mediated influence of the project deliverables on the social outcomes, we modelled the project levels as having an influence on the outcomes supply rate, and not flowing into the outcomes themselves.

As an auxiliary variable - the legitimacy factor is in this scenario a result of project efficiency as appreciated by the donors through adequate reporting and by the beneficiaries through the perceived social outcomes of nonprofit activity. The relationship between the legitimacy factor and the financing rate accounts for the reinforcing loop from the causal loop diagram (Figure 1).

Detailing the staffing related issues in nonprofits as contextualized by this framework is given through the following observation of the dynamics of the resources flows: if the nonprofits cannot find adequate financing for their project, they will appeal mainly to volunteering work, which will lead to substandard outcomes, leading in its own turn to less financing of future nonprofit pursuits and less paid staff. This reinforcing causal loop might of course by driven in the opposite direction through increasing funding leading, in the last instance, to retaining highly qualified staff in nonprofits. In the model, attracting qualified stuff is also influenced by the legitimacy factor, an increase factor leading to a more attractive organizational setting for highly qualified employees.

The information exchange between the funders and the nonprofits is usually governed by contracts and rule-based procedures establishing the minimum informational content of periodic project reviews. From a system dynamics perspective, establishing a connection between the time delays of the system, the updates of the feed-back loops, and the periodicity of the project reviews is of paramount importance. For instance, the practice to ask for quarterly reviews is disconnected form the calendar of project deliverables and, at times, even from the completion of budget execution for a specific quarter. The information flow between nonprofits and the beneficiaries is done through regular meetings and interviews and should be synchronized with the delays which might occur between outcomes delivery and the perceived satisfaction by the beneficiaries. Both of these information management measures also ensure for legitimacy status, along with project efficiency appraisal. The synchronization of reporting with major system events affecting the stocks is also bearing on managerial appraisal, the reporting is done before major deliverables and outcomes, it leads to a diminished appreciation of the managerial effort. In terms of the content of the project reviews, if the reporting process is encouraging short term success, it could encourage a lack of interest in long term sustainability.

Since the system presented is heavily dependent on the completeness and accuracy of the information about the relevant stocks, the functioning of the system entails the problems associated with informational asymmetry. In the real world, the information pertaining to the system information is incomplete and asymmetrically distributed, this state of affairs leads not only to inefficacy, when it comes to reaching the goal of satisfying social needs in due time, but also to moral dilemmas when those who share the incomplete asymmetric information do not happen to share the same interests [28]. The main three agents in the system - funders, nonprofits and beneficiaries - should address these issues through 
procedures such as: transparent policies and contracts, clear and timely reporting tools and techniques; incentive alignment proxies that would stimulate truthfulness [28].

Large nonprofits, or alliances thereof, while taking advantage of information delays in the system, could establish a temporary monopoly on information about the beneficiaries and their current needs. The puts them in the situation where they could balance the power of the resource holders by making self-fulfilling prophecies based on the gap between apparent and real information on the stocks of projects, outcomes and needs. Balancing the financers power is at times performed through nonprofit alliances lobbying for less tight reporting requirements and regulations, when those requirements are placing a great deal of organizational burden in project management processes, and while ensuring a higher degree of the transparency of spending, they have a small contribution to social outcomes.

\section{Strategic positioning and strategic decisions in a dynamic setting}

The strategic situation of the multi-project nonprofit is given mainly by the levels of funding and social needs, combining the variance of these two levels offers a map of strategic situations facing nonprofits. Four main strategic contexts are delineated by the funding/needs combinations - as in Figure 3.

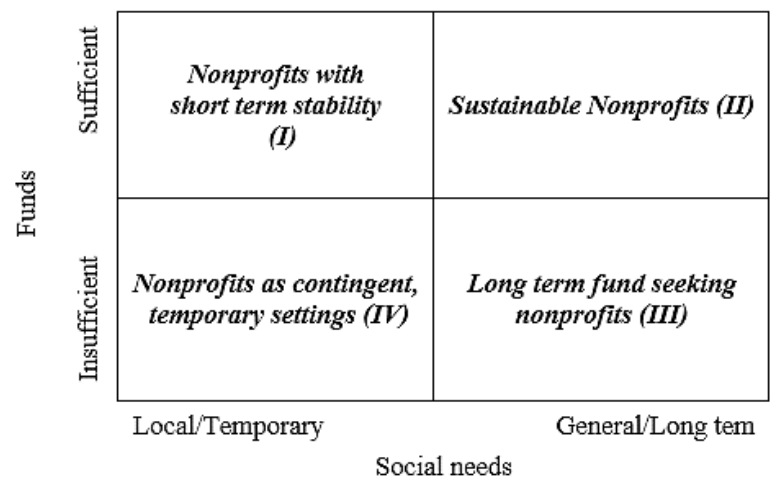

Fig. 3. The strategic context of multi-project nonprofits in terms of funds and needs

These four contexts are: nonprofits with short term stability (quadrant I), sustainable nonprofits (quadrant II), long term fund seeking nonprofits (quadrant III), nonprofits as contingent temporary settings (quardant IV) Identifying the quadrant that best describes the strategic position of a nonprofit allows managers to express their agency in a feedforward move, by bringing structural changes to the system, changes which would ensure organizational sustainability. All the four quadrants presuppose a certain degree of project efficiency, if a nonprofit fails to deal with the project constraints, it will lack ongoing financing and not supply for the needs, but this result is not given by the system presented thus far, and it can be addressed by classical project management techniques, not necessarily by system dynamics approaches.

Nonprofit sustainability is hindered by low levels of funding supplied and needs to be addressed. While stimulating and, in a broader sense, instilling needs is seen as legitimate in a business setting, it would be counter-missional for nonprofits to control, let alone enhance, the needs of their beneficiaries. In this respect, social needs accumulations are seen as independent of nonprofit behaviour (their incoming flow is hence, as depicted above, outside the boundaries of the model presented here) and the ideal nonprofit success 
would consist in completely meeting those needs. In an environment changing at a steeper pace, nonprofits might not be able to collect enough information on the magnitude of needs and hence their reaction might lead to changing their mission, which in its own turn shifts their outcomes towards different beneficiaries and social needs.

In cases where insufficient funding is trying to cover perennial social needs one may foresee a radical change of the system presented herein, a change determined by factors such as: restructuring the social and economic environments which led to the long term/structural need - hence dissolving the need; the complete organizational integration between the financers and the nonprofit (through government agencies or corporate social responsibility programs - for public and private financers, respectively) - radically diminishing transactional costs, delivery delays and informational asymmetry. There are also cases where the membership of the nonprofit forms at the same time, in some respect, its own beneficiary base, in associations whose missions are mainly concerned with some peculiar needs of their associated members - as it happens, for example, in professional organizations. This situation is asking for a conflation of the outcomes-needs flows, since the deliverables are self-consumed at the non-profit level. If the associated members also contribute to the funding of the projects, through various fees or in kind donations, then the tri-partite relation financers-nonprofits-beneficiaries is actually transformed in a selfcontained system where all the flows of resources and outcomes are endogenous to the nonprofit organization.

One way to address long term funding scarceness is through nonprofits engaging in income generating or commercial activities. While pursuing for profit activities, the nonprofits face the inherent tension of balancing resources allocation between their commercial activities and their mission related projects. Moizer and Tracey [11] use causal loops to indicate and evaluate the three main strategic options for toning down this tension, these strategies are: separating the social and commercial mission, integrating social and commercial mission, and building alliances with for profit businesses. Assessing the reinforcing loops of revenue generation and organizational legitimacy - on one hand, and the balancing loop of social action, the aforementioned authors show that each strategy presents its own challenges and the role of a causal loop model is two make the management aware of the sustainably impact of their decisions in balancing the commercial-social tension. From a general systems theory perspective [29], commercial activities are the natural result of nonprofits being open (bertallanfyian) systems acting towards stability. Business type activities serving in this setting as self-regulatory mechanisms enabling nonprofits to be mission compliant in hostile environments that hinder resource stability. This approach is theoretically penetrating, but it does not give any role to the feed-back loops existing between the commercial and the nonprofit activities of the same entity. For profit activities might also be a solution when donors are supplying enough resources, but are also pushing for mission displacement [29]. Where nonprofit social activities are funded by businesses, they might as well be replaced with the business's own corporate social responsibility programs, diminishing hence transaction costs.

Since we defined nonprofit sustainability as aiming for continuous improvement, a sustainable nonprofit (the quadrant II type - having enough funding for addressing a structural social need) at a given juncture might decide to expand the number of simultaneous projects and be able to set as a goal reaching more beneficiaries, or looking for social impact through societal solutions which in the long run dissolve a social problem altogether.

To add up a dynamic dimension to the matrix of strategic contexts the principal question to be answered is: what information should dictate how often the nonprofit management should assess their strategic contexts in terms of funding and social needs? 
The information required for such an assessment is given by the scope and schedule of the projects, the funding available is revealed through the periodicity of project reviews, whereas the status of the social needs is apprised through regular meetings with the beneficiaries, meetings especially related to project milestones. This solution is consistent with the requirement for ongoing stakeholder consultancy.

\section{Conclusions}

There is no model which offers a complete description of reality, but progress is achieved when the modelling process provides more clarity on issues where decision variables, constraints and environments seem to be blurry and escape stable identification and analysis.

This paper aimed at using the insights of system dynamics modelling for analysing the prospects of sustainability for nonprofits operating in multi-project contexts. The system dynamics concepts of causal loops, stock and flow dependencies were used to depict the complex relationships between projects, funding sources and social outcomes. The goal of the system consists in diminishing the identified social needs of the beneficiaries - trough supplying an array of outcomes mediated by project deliverables and resourced by means of contracting various financers The construal of a stock and flow model for this goal oriented system entailed defining the boundaries, the main stocks, flows and the decision rates.

This approach has led to the identification of the systemic threatening to nonprofit sustainability and of the dynamic nature of managerial decisions, in the context of the interactions between nonprofit organizations, their beneficiaries and funding agencies. The peculiarities of these hindering systemic factors are mainly related to the delays of the information flows and to the various informational asymmetries characterizing the information flows. If policy measures are taken by financers neglecting the time delays induced by the pace of project delivery, they will generate highly oscillatory behaviour of the system, leading to instability in terms of service reliability. In terms of the main stocks of the model, the authors portrayed four categories of strategic domains for non-profit multiproject management.

While some suggestions on the equations of the model were indicated, one limit of the work provided in this paper (and an opportunity for further research) is given by the requirement to assign equations to the stocks, rates and auxiliary variables and to calibrate these with known values from the real world system Since the model presented is a generic one, the first step for its real world usage would consist in a proactive analysis performed by nonprofit managers and stakeholders in customizing the model according to their specific organizational settings. This proactive approach can transform the customized model into a powerful tool for understating the dynamic processes affecting nonproft sustainability and for weighting policies that drive the system.

\section{References}

1. J.D. Sterman, Business dynamics: Systems thinking and modeling for a complex world (McGrawHill, New York, 2000)

2. W.W. Powell, R. Steinberg (Eds.), The Nonprofit Sector - A Research Handbook, 2nd Ed. (Yale University Press, New Haven \& London, 2006)

3. G.P. Richardson, Syst. Dyn. Rev. 27, 219-243 (2011)

4. R.J. Chapman, Int. J. Proj. Manag. 16, 235-247 (1998)

5. C.C. Chikere, J. Nowka, Int. J. Sci. Res. 5(9), 1-7 (2015)

6. V. Valentinov, S. Heilscher, I, Pies, Econ. Syst. 39, 491-501 (2015) 
7. G.P. Richardson, Feedback thought in social science and systems theory (University of Pennsylvania Press, Philadelphia, 1991)

8. R.L. Ackoff, Recreating the Corporation - A Design of Organizations for the $21^{\text {st }}$ Century (Oxford University Press, Oxford, 1999)

9. S. Cho, D.F. Gillespie, Nonprofit Volunt. Sect. Q. 35, 493-509 (2006)

10. J.S. Tucker, J.C. Cullen, R.R. Sinclair, W.W. Wakeland, J. Appl. Behav. Sci. 41, 482-502 (2005)

11. J. Moizer, P. Tracey, Syst. Res. 27, 252-266 (2010)

12. A. Rodrigues, J. Bowers, Int. J. Proj. Manag. 14, 213-220 (1996)

13. J.M. Lyneis, D.N. Ford, Syst. Dyn. Rev. 23, 157-189 (2007)

14. T.K. Abdel-Hamid, J. Syst. Soft. 22, 151-165, (1993)

15. M.H.A. Hendriks, B. Voeten, L. Kroep, Int. J. Proj. Manag. 17, 181-188 (1999)

16. F.P. Brooks, The Mythical Man-Month - Essays in software engineering - Anniversary Edition (Addison-Wesly, Boston, 1995)

17. Ventana Systems, PLE, https://vensim.com/ (2020)

18. D. Kim, W. Cho, B. Allen, J. Soc. Sci. DOI: 10.1080/03623319.2020.1799174 (2020)

19. O. Weber, J. Innov. Econ. 11, 149-171 (2013)

20. R.L. Ackoff, J. Magdison, H.J. Addison, Idealized Design (Wharton School Pub., New Jersey, 2006)

21. J.W. Forrester, Syst. Dyn. Rev. 3, 136-149 (1987)

22. A.A. Alchian, H. Demsetz, Am. Econ. Rev. 62, $772-795$ (1972)

23. B.A. Seaman, D.R. Young (Eds.), Hanbook of Research on Nonprofit Economics and Management (Edward Elgar, Cheltnham, 2010)

24. J.S. Wholey, H.P. Hatry, K.E. Newcomer (Eds), Handbook of Practical Project Evaluation, 2nd ed. (John Wiley \& Sons, San Francisco, 2004)

25. Nicholls J, Lawlor E, Neitzer E, Goodspeed T. A guide to Social Return on Investment, https://neweconomics.org/2009/05/guide-social-return-investment

26. PWC. Measuring and managing total impact: $A$ new language for bussines, www.pwc.com/gx/en/sustainability/publications/total-impact-measurementmanagement/assets/pwc-timm-report.pdf

27. G. Van der Waldt, Administratio Publica 19, 2-20 (2011)

28. B.W. Husted, Organ. Stud. 28, 177-195 (2007)

29. L. Moeller, V. Valentinov, Syst. Pract. Action Res. 25, 365-370 (2012) 